\title{
Carboxylic Acid Production
}

\author{
Gunnar Lidén \\ Department of Chemical Engineering, Lund University, P.O. Box 124, 22100 Lund, Sweden; \\ gunnar.liden@chemeng.lth.se
}

Received: 21 August 2017; Accepted: 12 September 2017; Published: 14 September 2017

Keywords: biorefinery; natural carboxylic acid producers; fungi; bacteria; fermentation technology; downstream processing

Carboxylic acids are central compounds in cellular metabolism, and in the carbon cycle in nature. Carbon dioxide is captured from the atmosphere and enters living cells through the formation of carboxylic groups, and it is released from living cells by the decarboxylation of carboxylic acids. The aerobic extraction of free energy from sugars in cellular respiration hinges on the ingeniously designed tricarboxylic acid cycle involving a range of carboxylic acids, and the reactivity of the carboxylic group with amino- or hydroxyl-groups enables the formation of peptide and ester bonds in macromolecules. The functionality of the carboxylic group is, not surprisingly, also of huge importance in the industrial world for a wide range of applications. The loosely bound hydrogen provides weak acid functionality, much desired for food industry applications in preservatives and flavor compounds, and citric acid is one of our oldest and quantitatively largest industrial fermentation products. The presence of two carboxylic groups, or a combination of one carboxylic group and another functional group, make the compounds interesting building blocks for polymer production. Several carboxylic acids, including e.g., lactic, succinic, 3-hydroxypropionic and itaconic acids, have been recognized as suitable platform chemicals for a foreseen growing non-fossil based industry. Economic margins are, however, narrow when competing with petroleum-based products. Microbial production strains, fermentation technology and - not least-downstream processing, all need to be improved to enable a viable commercial production and speed up the transition towards non-fossil-based production of carboxylic acids. This special issue is devoted to the microbial production of carboxylic acids.

Several reviews give updates on the production of some of the most interesting acids. Succinic acid is one of the products for which bio-based production has increased most rapidly in recent years. Nghiem et al. [1] give an overview of both the microbial production and the state of commercialization of this acid. Malic acid, a close neighbor to succinic acid in the tricarboxylic acid cycle, is treated by West [2], with a special focus on use of biofuel related co-products as substrates (e.g., corn stover, straw, and glycerol, but also syngas). Interestingly, one way to produce malic acid is via poly $\beta$-L-malic acid, which accumulates intracellularly in Aspergillus pullulans. 2-oxopropanoic acid is the proper (but rarely used) name for pyruvic acid. Many metabolites are at metabolic crossroads, but few are more centrally localized in terms of major pathways than pyruvate. Maleki and Eiteman [3] give a detailed account of the involved pathways, and review engineering and process strategies for pyruvate production. Propionic acid is a fermentation product which has received less attention than the previously mentioned acids. Gonzalez-Garcia et al. [4] cover this acid in their review, which includes an in-depth analysis of the energetics of various possible pathways towards propionic acid. A broader review by Murali et al. [5], covering the production of several acids, such as acetic, butyric, lactic, and propionic acid using microbial consortia, is also included in this issue.

The choice of substrate is clearly crucial in bio-based production, primarily for economic reasons but also for environmental reasons. Couvreur et al. [6] report work on response surface optimization of growth media for Lactobacillus reuteri based on agro-industrial by-product streams, and the subsequent 
use of L. reuteri for the bioconversion of glycerol to 3-hydroxypropionic acid. A strong impact on the product distribution was found in comparison to a standard medium. A two-stage process was also used by Alcantara et al. [7] in their work on succinic acid production by a mixed fungal culture of Aspergillus niger, Trichoderma reesei, and Phanerochaete chrysosporium. Here, the objective was to use the enzyme production ability of the fungi in solid state fermentation, with $A$. niger and T. reesei grown on soy bean hulls and P. chrysosporium grown on birch wood chips, as well as their metabolic capacity, to form succinate in a second stage slurry fermentation. Papadaki et al. [8] also examined fungal carboxylic acid production in their study on fumaric acid production by Rhizopus arrhizus. The focal point of the investigation was the effect of the fungal morphology on productivity and yield. The authors found that higher titers and yields were obtained with dispersed mycelia rather than pellets. Corn stover is another widely available agro-residue, which after hydrolysis can be used as a substrate. Nelson et al. [9] report on the production of a mixture of butyric and hexanoic acid by the anaerobic bacterium Megasphaera elsdenii isolated from sheep rumen. A common problem in carboxylic acid production is the end-product inhibition, which limits final titers. Through in situ product removal by a reactive extraction system, end product inhibition could be minimized, allowing total titers of more than $55 \mathrm{~g} / \mathrm{L}$ to be reached in the extract in a glucose fed-batch process.

Anaerobic digestion is an established waste treatment method, which primarily gives methane as a valuable product. Anaerobic digestion is a complex multistage process involving an adapted and selected consortium of microbes, which is normally not fully characterized. The overall process is an initial formation of short chain carboxylic acids, also known as "volatile fatty acids", which are in turn converted to methane. Queiros et al. [10] selected an inoculum and process conditions such that the methanogens would be inhibited, thereby stopping the process at carboxylic acids. A mixture of carboxylic acids - acetate, propionate, butyrate, valerate, and lactate-was obtained in long-term trials using spent sulfite liquor from hardwood.

Purification is a crucial problem for process economics, in particular when using hydrolyzates or waste streams as substrates. Figueira et al. [11] present a method for the purification of fumaric acid from Eucalyptus spent sulfite liquor reaching sufficient purity for polymer production. With a two-step precipitation method, based on the low solubility of fumaric acid, followed by activated carbon treatment, sufficient purity could be obtained with recovery yields of about $80 \%$ from broths holding $50 \mathrm{~g} / \mathrm{L}$ of fumarate.

To conclude, there is clearly progress towards a significant increase in commercial bio-based carboxylic acid production, although many challenges remain. Titers, yields, and productivities must continue to increase, and to this end a combination of targeted engineering and evolutionary engineering will likely be used. Screening for new natural producers will be important-primarily to supply novel enzymes, but new host organisms or strains may also be found. A shift in carbon source from glucose to biomass-derived sugars will give additional requirements on host organisms in terms of robustness to impurities and utilization of multiple sugars. Downstream processing will also be strongly affected by such a shift, where it is important to keep in mind that additional separation costs must not exceed the price difference between the substrates.

Acknowledgments: The author is grateful for research support in this field through the EU contracts BRIGIT (grant number FP7-311935) and Biorefine-2G (grant number FP7-613771).

Conflicts of Interest: The author declares no conflict of interest.

\section{References}

1. Nghiem, N.P.; Kleff, S.; Schwegmann, S. Succinic Acid: Technology Development and Commercialization. Fermentation 2017, 3, 26. [CrossRef]

2. West, T.P. Microbial Production of Malic Acid from Biofuel-Related Coproducts and Biomass. Fermentation 2017, 3, 14. [CrossRef]

3. Maleki, N.; Eiteman, M.A. Recent Progress in the Microbial Production of Pyruvic Acid. Fermentation 2017, 3, 8. [CrossRef] 
4. Gonzalez-Garcia, R.A.; Tim McCubbin, T.; Navone, L.; Stowers, C.; Nielsen, L.K.; Marcellin, E. Microbial Propionic Acid Production. Fermentation 2017, 3, 21. [CrossRef]

5. Murali, N.; Srinivas, K.; Ahring, B.K. Biochemical Production and Separation of Carboxylic Acids for Biorefinery Applications. Fermentation 2017, 3, 22. [CrossRef]

6. Couvreur, J.; Teixeira, A.R.S.; Allais, F.; Henry-Eric Spinnler, H.-E.; Claire Saulou-Bérion, C.; Clément, T. Wheat and Sugar Beet Coproducts for the Bioproduction of 3-Hydroxypropionic Acid by Lactobacillus reuteri DSM17938. Fermentation 2017, 3, 32. [CrossRef]

7. Alcantara, J.; Mondala, A.; Hughey, L.; Shields, S. Direct Succinic Acid Production from Minimally Pretreated Biomass Using Sequential Solid-State andSlurry Fermentation with Mixed Fungal Cultures. Fermentation 2017, 3, 30. [CrossRef]

8. Papadaki, A.; Androutsopoulos, N.; Patsalou, M.; Koutinas, M.; Kopsahelis, N.; de Castro, A.M.; Papanikolaou, S.; Koutinas, A.A. Biotechnological Production of Fumaric Acid: The Effect of Morphology of Rhizopus arrhizus NRRL 2582. Fermentation 2017, 3, 33. [CrossRef]

9. Nelson, R.S.; Peterson, D.J.; Karp, E.M.; Beckham, G.T.; Salvachúa, D. Mixed Carboxylic Acid Production by Megasphaera elsdenii from Glucose and Lignocellulosic Hydrolysate. Fermentation 2017, 3, 10. [CrossRef]

10. Queirós, D.; Sousa, R.; Pereira, S.; Serafim, L.S. Valorization of a Pulp Industry By-Product through the Production of Short-Chain Organic Acids. Fermentation 2017, 3, 20. [CrossRef]

11. Figueira, D.; Cavalheiro, J.; Sommer Ferreira, B. Purification of Polymer-Grade Fumaric Acid from Fermented Spent Sulfite Liquor. Fermentation 2017, 3, 13. [CrossRef]

(C) 2017 by the author. Licensee MDPI, Basel, Switzerland. This article is an open access article distributed under the terms and conditions of the Creative Commons Attribution (CC BY) license (http://creativecommons.org/licenses/by/4.0/). 